\title{
Glass Surface Decoration by Sandblasting Technique: A Case Study
}

\author{
Fatuyi, O.A. ${ }^{1} \quad$ Aliu, E.T. ${ }^{2}$ \\ Department of Industrial Design, School of Environmental and Environmental Technology, \\ Federal University of Technology, PMB 704, Akure Ondo State, Nigeria
}

\begin{abstract}
The properties of glass; mechanical robustness, dielectric properties and transparency make it very useful for micro-machining decoration particularly in architectural designs and beautification. In this paper, sandblasting, ONE OF the commonest glass designing techniques was used to etch the name and logo of "THE FEDERAL UNIVERSITY OF TECHNOLOGY, AKURE" on a piece of glass of dimension $600 \mathrm{~mm} \times 400 \mathrm{~mm} \times 4 \mathrm{~mm}$. The method made use of a particle jet directed towards the glass for material removal by mechanical erosion via the impingement of high velocity abrasive particles. The result gave rise to a well finished glass material, useful for office design and walk way design within the University.
\end{abstract}

Keywords: Sandblasting, etching, glass micro-machining, abrasive blasting, fabrication, glass, design.

DOI: $10.7176 / \mathrm{ADS} / 72-03$

Publication date: April $30^{\text {th }} 2019$

\section{Introduction}

The Enviro-Management \& Research, Inc., (2001) defines "Abrasive blasting” as a process of cleaning and finishing of materials by forceful direction of an abrasive media applied either dry or suspended in a liquid medium, against the surface of the workpiece. The process of abrasive blasting began in 1904. Today, it is used to: clean a surface by removing unwanted rust, scale, paint, etc., in preparation for painting, anodizing, welding, or other processes which require a clean surface (Enviro-Management \& Research, Inc., 2001). It also finds application in deburring, removing tooling marks, or otherwise finishes a crude product as well as in metallurgical change of properties of materials or stress relieve of a part by the peening action of multiple impactions. Abrasive blasting can as well be used to produce a desired matte or decorative finish, thereby providing an actual cutting or inscription of partially masked parts, such as tombstones, ceramics, glass and silicon. The process is also useful in removing flashing (excess material) from molded plastic or rubber (EnviroManagement \& Research, Inc., 2001). Abrasive blasting is utilized for many different purposes by foundries, shipyards, steel fabrication plants, special purpose job and machine shops, gas transmission stations, steel mills, structural steel supply yards, building cleaners, wineries, breweries, canneries, rubber manufacturers, painting contractors, plastic manufacturers, welders, wood shops and furniture manufacturers, plating and anodizing shops, aircraft manufacturers, electronic manufacturers, petrochemical companies, memorial monument markers, and many others. Abrasive blasting is more of a general name for application of abrasives to material surfaces. Van Toan, Toda, \& On, (2016) explained that glass micromachining on the other hand is a more specific name for application of varieties of abrasive designs on the surface of glass. These designs (treatment) could come in various colors and shapes and are used primarily to diffuse light, reduce glare and obtain a translucent and beautiful appearance on glass surface. It can be used for both interior and exterior applications. For interior designs, glass micromachining is useful for; dividing walls; as wall coverings; award plaques; office partitions and enclosures; shower and bath enclosures; floors, stairs and railings; doors; displays and shelving; elevator cabs; kitchen cabinets; furniture components. For exterior applications, design glass surfaces can be useful for sealed units, spandrels, balustrades, bus shelters, skylights, canopies, atriums, doors e.t.c. There are several techniques of glass micromachining in existence today, including drilling, milling, laser, sandblasting (Wensink, Berenschot, Hanse, \& Elwenspoel, 2000), wet etching (Grosse, Grewe, \& Fouckhardt, 2001), dry etching (Lin, Hsu, Yang, Wang, \& Fang, 2008), glass molding techniques, etc.

Sandblasting is like spray painting but instead of paint you blow an abrasive material with compressed air to etch the surface being blasted. A "resist" material is applied to the glass, the desired design is cut into the resist to produce a stencil, and the areas you want to be etched removed(Van Toan, Toda, \& On, 2016). In other words, "Sandblasting can be referred to as a process where compressed air is mixed with abrasive media and shot at targeted areas of glass or mirror to etch a pattern, shape, or design of one's choice". This process changes the surface of the glass from smooth to rough. Drilling, milling and laser methods are usually used for quite large pattern sizes and face problems with small structures (Van Toan, Toda, \& On, 2016). Sandblasting technique leads to a rough etching surface and has difficulty in the fabrication of small patterns below $100 \mu \mathrm{m}$. It is a technique in which a particle jet is directed towards a target (sample) for material removal by mechanical erosion via the impingement of high velocity abrasive particles. The sandblast process can be used for etching various materials such as glass (Wensink, Berenschot, Hanse, \& Elwenspoel, 2000), ceramics (Toan, Miyashita, Toda, 
Kawai, \& Ono, 2013)(example: LTCC (low temperature co-fired ceramics)), and silicon. Glass decorations have become a rather common trend especially within the $21^{\text {st }}$ century. In architectural structures, etched design in homes and offices add to the quality of buildings. In exterior settings, sandblasted glass mirrors can help create eye-catching designs which can cost lots of money as the process often requires a lot of time and expertise.

\section{History of Etching}

There is no strong evidence for the actual history of etching. Infact, different literatures have given differing ideas as to the first etched work (Marion \& Omri, 1998). However, the practice of making prints from etched metal plates grew out of the custom of etching designs on armour and was adopted by printmakers as an easy way of engraving, a process of making prints from metal plates incised with a tool called a "burin". A 2014 publication by Encyclopaedia Britannica claims that the first dated etching was made in 1513 by the Swiss artist Urs Graf, who printed from iron plates. Albrecht Dürer, a popular German graphic artist made only five etchings. In his "Cannon" (1518), he tried to imitate the formal, premeditated quality of engravings, revealing that etching's spontaneity and flowing line were as yet not valued in northern Europe. The 16th-century Italian artist Parmigianino, however, made etchings with easy, graceful strokes that show his full understanding of the technique. In France, the printmaker Jacques Callot used etching as an aid to engraving in his series "Miseries of War" (1633) (Dashiell, 1980). He not only incised the metal when drawing through the ground but also reinforced the lines with an engraver's burin after the plate had been exposed to acid. Of the entire artist that carried out early works on etching, Rembrandt Harmenszoon van Rijn's work stands out (Marion \& Omri, 1998). Hence, he is often referred to as the greatest master of pure etching. He abandoned all links with engraving and produced over 300 etchings with unsurpassed virtuosity, using the freedom inherent in the medium to render light, air, and space (Encyclopædia Britannica, 2014). The 18th-century Venetian artists Giovanni Battista Tiepolo and Canaletto also used etching to capture atmospheric effects, and the Roman etcher and archaeologist Giambatista Piranesi used etching to serve his fantasy in his series "Carceri" (c. 1745), a group of interior views of foreboding imaginary prisons. More horrific was the series "Los desastres de la guerra" (1810-14), by the Spanish artist Francisco de Goya. Unlike most of his other prints, Goya's "Desastres" were done mainly in etching with little aquatint (Encyclopædia Britannica, 2014). During the late 18th and early 19th centuries, softground etching, or vernismou, became current. This technique involves drawing with a pencil on a sheet of paper placed on a copperplate coated with an extremely soft, sticky ground. The ground adheres to the paper wherever the pencil passes, leaving the metal exposed in broad, soft lines. The plate is exposed to acid and, when printed, yields results similar to pencil or chalk drawings. It was primarily a reproductive technique but was used by the 18th-century English artists Thomas Gainsborough, John Sell Cotman, and Thomas Girtin for original designs, mainly landscapes. In the late 19th century, Edgar Degas, Camille Pissarro, and Mary Cassatt used the then moribund technique for artistic ends, and their work fostered a revival in the 20th century (Grosse, Grewe, \& Fouckhardt, 2001).

Another group of literatures believe that the origin of etching can be traced to Daniel Hopfer, a German print maker (Omri, 1997). Hopfer was a craftsman who decorated armour in this way, and applied the method to printmaking, using iron plates (many of which still exist). Apart from his prints, there are two proven examples of his work on armour: a shield from 1536 now in the Real Armeria of Madrid and a sword in the Germanisches National museum of Nuremberg. An Augsburg horse armour in the German Historical Museum, Berlin, dating to between 1512 and 1515, is decorated with motifs from Hopfer's etchings and woodcuts, but this is no evidence that Hopfer himself worked on it, as his decorative prints were largely produced as patterns for other craftsmen in various media (Omri, 1997). The switch to copper plates was probably made in Italy, and thereafter etching soon came to challenge engraving as the most popular medium for artists in print making(Lin, Hsu, Yang, Wang, \& Fang, 2008). Its great advantage was that, unlike engraving where the difficult technique for using the burin requires special skill in metalworking, the basic technique for creating the image on the plate in etching is relatively easy to learn for an artist trained in drawing (Encyclopædia Britannica, 2014). On the other hand, the handling of the ground and acid need skill and experience, and are not without health and safety risks, as well as the risk of a ruined plate.Farb, (1978) explained that prior to 1100 AD (Encyclopædia Britannica, 2014), the New World Hohokam independently utilized the technique of acid etching in marine shell designs. Jacques Callot (1592-1635), a French painter and artist made important technical advances in etching technique. He developed the échoppe (a type of etching-needle), with a slanting oval section at the end, which enabled etchers to create a swelling line, as engravers were able to do (Marion \& Omri, 1998).Callot also appears to have been responsible for an improved, harder, recipe for the etching ground, using lute-makers' varnish rather than a waxbased formula (Encyclopædia Britannica, 2014). This enabled lines to be more deeply bitten, prolonging the life of the plate in printing, and also greatly reducing the risk of "foul-biting", where acid gets through the ground to the plate where it is not intended to, producing spots or blotches on the image. Previously the risk of foul-biting had always been at the back of an etcher's mind, preventing too much time on a single plate that risked being ruined in the biting process (Encyclopædia Britannica, 2014). Now etchers could do the highly detailed work 
that was previously the monopoly of engravers, and Callot made full use of the new possibilities. Callot also made more extensive and sophisticated use of multiple "stoppings-out" than previous etchers had done.

\subsection{Sandblasting as a method for etching glass mirror}

Sandblasting involves the use of an abrasive material, a resist material, a sandblast cabinet and some other equipment. The function(s) of these items are explained below

\subsubsection{Resist materials}

The choice of resist material for etching work is a function of the kind of blasting to be carried out. Table 1 shows the usage of each type of resist material available in the market. Wensink, Berenschot, Hanse, \& Elwenspoel, (2000) explainedthat it is important to consider the following characteristics of the resist material prior to selection

- How tough - will it stand up to aggressive blasting?

- How adhesive - how well will it stay stuck?

- How soft - how easily will it bend over curves?

- How expensive - will cheaper material work?

Table 2.1: Types of resist material (Glasscampus, 2012)

\begin{tabular}{ll}
\hline Resist type & Usage details \\
\hline Paper resist & $\begin{array}{l}\text { Paper resist is useful if surface etch is intended. For this resist type, a low pressure is required } \\
\text { for blasting. Vinyl coated paper is placed on some part of the surface to be etched using } \\
\text { masking tape or adhesive. }\end{array}$ \\
Vinyl Resist & Vinyl can be used on a variety of surface. It is one of the most frequently used resist types
\end{tabular}

Vinyl Resist Vinyl can be used on a variety of surface. It is one of the most frequently used resist types and comes in a variety of thicknesses. It is able to contain aggressive blasting with as low as 8 mil thickness. It can work well on surface etch and on deep carved glass as well as stone. It feels great on all flat works and on straight curves like cylinders but too stiff to bend over multiple curves. For this, you either need a softer and more flexible material or, as most artisans do, just cut slits in it to lap over to allow for curvature

Rubber resist This resist is usually selected for extremely aggressive blast projects or for projects where there is a need to bend over multiple curves.

Photo Resist Photo resist is a stencil created by printing onto a transparent material that allows UV light to pass through. It can be done on a laser or ink printer but only with special paper. This creates a negative of the image. Photo resist produces a stencil that allow for extensive and intricate detail. Creating photoresist stencils is easy to screw up, and requires a good understanding of sandblasting effects. It is best handle by expert hands. To experiment with photoresist, it maybe a good idea to start by buying some of the premade photoresist stencils.

Liquid Resist This is a way to brush on shapes for sandblasting. Asphaltum, shellac, or melted wax are commonly used to paint a material as liquid resists. Asphaltum and shellac will leave crisp lines but wax erodes during blasting and leaves fuzzy lines. A reliable working material as liquid resist is the liquid latex use to make molds.

\subsubsection{Types of abrasive materials}

Different types of materials are available from very fine to extremely coarse. The coarser the grit, the faster it will blast and the rougher the texture created (Grosse, Grewe, \& Fouckhardt, 2001). Most decorative sandblasting on glass is done with 100 or 120 grit with finer grits used more for special effects and coarser grit mostly for aggressive deep carving (Glasscampus, 2012).

Aluminum oxide: This is the most popular choice for many sandblasters. It is cheaper than silicon carbide but wears down much quicker and reduces the chance of reuse compared to silicon carbide (Kong, Minami, \& Esashi, 1997).

Sand: Sand is inexpensive and readily available, but produces silica dust when blasted (Li, Abe, \& Esashi, 2000). This is quite harmful if inhaled so blasting with sand should only be done under very carefully controlled conditions while wearing a respirator that ensures you do not inhale any of the dust produced. Silicon carbide: Silicon carbide is much more expensive than aluminum oxide. It is harder and can be used many more times for subsequent sandblasting. The ability to use and reuse silicon carbide makes it cheaper in the end (Kong, Minami, \& Esashi, 1997). Aluminum oxide rounds off from one usage and stops working as an abrasive. Silicon carbide is too hard to wear down but instead breaks into smaller grit which will still work as an abrasive. It also has the appealing feature of producing bright sparks where it hits the glass during blasting. This makes it easy to see exactly where the grit is hitting - a terrific aid for fine detailed work (Grosse, Grewe, \& Fouckhardt, 2001). Although the finishes produced by the different grits look quite similar, the textures feel a lot different. They also reflect light differently. 60 or 80 grit abrasive would normally be used only when you want to remove a lot of material in a hurry (Glasscampus, 2012). Finer grit is used either when you intentionally want the etching effect to be very slow or you want a smoother finish. The finer the grit, the longer it takes to etch 
(Lin, Hsu, Yang, Wang, \& Fang, 2008). 600grit is so extraordinarily fine.

Garnet: Garnet can be a useful abrasive in the absence of all the aforementioned ones. The disadvantage however is that it is softer than the other abrasives so it will take much longer to do the job.

\subsection{Sandblasting techniques}

There are a couple of techniques of sandblasting. Each technique is able to create different effects. This section discusses some of the available techniques

\subsubsection{Carving}

This is when the glass has been blasted in variable curves to create contour (Omri, 1997). It takes a lot of time than other sandblasting techniques. Carving also requires a lot of skills and is usually done at high pressure from close distance. For this reason it is important to use an especially strong resist that will stand up to the aggressive blasting needed to carve deeply into the glass (Wensink, Berenschot, Hanse, \& Elwenspoel, 2000). Like multistage sandblasting, carving requires planning in advance to create the desired effect. It is designed to be seen from the smooth side, hence, one must keep this in mind when blasting the varying curves and depths to create contrast and perspective. It is like mold making where you think positive but do negative. When carving has been designed, it is important to flip it before cutting the stencil. There are certain factors to consider to carry out effective carving under sandblasting (Van Toan, Toda, \& On, 2016). They include;

- Variation - do you want a uniform depth or do you want it varied?

- Depth - how deep do you want to carve?

- Perspective - do you require a negative curve or a positive one?

- Contrast - how strong a difference do you want?

Carving is usually done on thick glass (Toan, Miyashita, Toda, Kawai, \& Ono, 2013). 1/4" is the most common but a thicker glass will allow for even more dramatic effects. Surface etching and shading are done by blasting straight on. In carving, the angle of the gun is changed frequently to create different curves and contour shapes.

\subsubsection{Surface etching}

This a single uniform blasting that produces a uniform texture. It can technically be referred to as the easiest of the sandblasting techniques. Although some artisans do not agree. One unique feature of surface etching is its ability to be able to produce virtually all kinds of design

\subsubsection{Multi-stage}

In multi-stage blasting, a strong contrast is created by removing part of the stencil and blasting long enough to cut deeply into the glass. This is followed by removing the rest of the stencil to surface etch the rest of the design. It can be done in two stages, or as many stages as you prefer. Since the objective is to create a strong contrast between the different parts, it is important to spend significantly different time blasting each stage. Where almost any design can be done as surface etching, and most can be carved, multi-stage designs usually need to be specifically designed to be done as multi-stage etching. It is important to plan a multi-stage design carefully so that components are blasted in the desired order to create the desired effect.

\subsubsection{Shading}

Shading is a multi-stage blasting technique. Where carving is done to create different depths of blast, shading is done to create different shades of blast ranging in tone from $0 \%$ to $100 \%$. Where other blasting methods produce a black and white variation, shading creates varying tones of gray. A skilled sandblaster can create shaded designs that look like black and white photographs. Because shading requires delicate control, it is usually done with pressure reduced and blasted from a greater distance than for surface blasting or carving. A pressure pot is especially helpful to maintain low but consistent pressure. Some artisans prefer to use unusually finer grit for shading projects. This technique takes considerable practice to master and is not recommended for beginners.

\subsection{Glass types for sandblasting}

Mirror Glass: Sandblasting on mirror is popular because it is especially attractive. A double image is created where the frosted image on the surface is reflected in the mirror backing. Etching the back of mirror can produce some unique effects. When the silver backing is removed, a clear frosted glass contrasting with mirror is seen. If light is installed behind it, the light will shine through the clear glass only. A common design by artisans is to install such mirrors in a medicine cabinet, so that the etched pattern lights up. For a particularly interesting look, such back etched mirrors can be installed over a colored surface so the etched parts show colors through the unetched mirror parts. It can be a solid color or a pattern. This can be a fun technique to experiment.

Flashed Glass: Flashed glass is glass in which a thin layer of color has been applied over another color. Usually with a clear or white base. Cutting through the thin colored top layer (with acid etching, engraving, or sandblasting) exposes the base color in contrast.

Tempered Glass: Tempered glass can be surface etched or shaded but cannot be deep carved. If you want to blast tempered glass, it is a good idea to use relatively fine abrasive and relatively low pressure. 
Blasting too deep will cause the glass to explode.

Laminated Glass: Sandblasting can be carried out on laminated glass. However, care must be taken not to blast through one layer of glass to expose the plastic between the layers of glass.

Kilnformed Flashed Glass: Flashed glass comes only in a limited selection of colors and only on white or clear base. In an experiment, Omri, (1997) to deduce ways to make a kind of flashed glass in a kiln in order to avoid color restrictions, the first attempt was a single layer of glass fully fused onto another single layer then a design sandblasted through the top layer. It was observed that vibration from the blasting cracked the base glass. A 3 layer was experimented which worked perfectly. Because the objective is to sandblast entirely through the top layer of glass, we decided to use 2 layers of $3 \mathrm{~mm}$ thick glass as a base and a layer of $2 \mathrm{~mm}$ thin glass on top. That started as $8 \mathrm{~mm}$ thick - then firing in the kiln to full fuse brought it down to $6 \mathrm{~mm}$ thick and reduced the top layer to only $1.5 \mathrm{~mm}$ and the base double layer to $4.5 \mathrm{~mm}$. For kiln-formed flashed glass you want to blast straight on until you're started to expose the 2nd layer color. This exposure almost always starts in the middle of the space being blasted. Once that exposure has started, blasting can be stopped straight on and switch to blasting on an angle so that one can blast more off near the edges than in the middle. Continue blasting and continue increasing the angle you blast at so you carve the glass along the edge of the stencil. Since blasting is for a long time and because you are blasting at a tight angle against the edge of the resist, it is important you have a sturdy resist that has been carefully applied. If not, blasting angle will lift the edge of the resist. The entire objection of applying resist is to have it stay in place and not lift. Once the sandblasting is complete, the project is fired in a kiln to tack fuse temperature. This softens off the harsh edges from blasting and puts a fire polish on the glass parts that were frosted by sandblasting.

Sandblasting with Kiln formed flashed glass takes a lot of time, particularly to blast through any significant area of glass $1.5 \mathrm{~mm}$ thick. It is note-worthy to state that when you sandblast for carving, you intentionally want to create curvature. For kiln formed flashed glass however, you want the opposite. You want to avoid curvature. The intention is to blast through the top layer of $1.5 \mathrm{~mm}$ glass down to the glass beneath it.

Iridescent Glass: Sandblasting to etch a pattern on iridescent glass creates a delicate but interesting effect. You can leave the etched parts frosted from the sandblasting or you can fire the glass in a kiln to fire polish the etched parts, the contrast between the solid colored parts and the iridescent parts is quite striking. This effect is most attractive on black iridescent glass but could be fun to experiment with other colors. Sandblasting iridescent glass to apply mica powder is a slick way to control the mica pattern and be sure you have a crisp well defined image. When fired in a kiln, mica will fuse to glass but will not stick to the metallic iridescent surface. By sandblasting a design that just surface etches through the coating you can provide a surface the mica will reliably fuse to.

\section{Materials and method}

The materials used include; a $600 \mathrm{~mm} \times 400 \mathrm{~mm} \times 4 \mathrm{~mm}$ glass mirror, a working table, masking tape, working blade, glass frame, sandblasting machine, cabinet. The glass is placed on a working table lying properly without disturbance. The table must also be properly placed so that it does not shake or bend. The surface of the mirror is covered with the sticker or masking tape so that the design to be effected can be traced out easily on the sticker. The designed logo and name is transferred onto the surface of the sticker. Transferring makes for easy cutting and tracing and subsequent blasting. The logo design is traced out with a machine-like working blade. This is one of the most delicate parts of the entire procedure. Here, the blade must be moved gently all across the traced surface so that the desired shape can be derived. The sticker-covered glass mirror is set under the sandblasting machine for subsequent and blasting of the surface of the mirror. Afterwards, the sticker is removed gently, so that we are left with a fairly dirty surface design. The next step is the cleaning of the glass mirror surface to remove any form of sandblasting dirt as well as dirt from tracing out sticker. Framing of the glass mirror is the final step in glass machining process. The designed glass is put in a frame for easy handling. It also makes the design ready to be presented as an award and/or gift. It is important that the dimension of the frame is equal to that of the designed glass frame. 


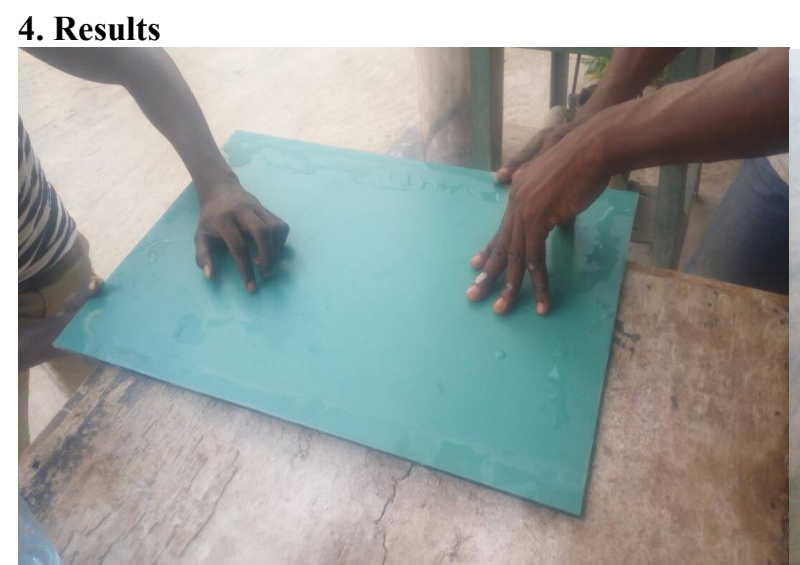

Setting the glass mirror on a working table

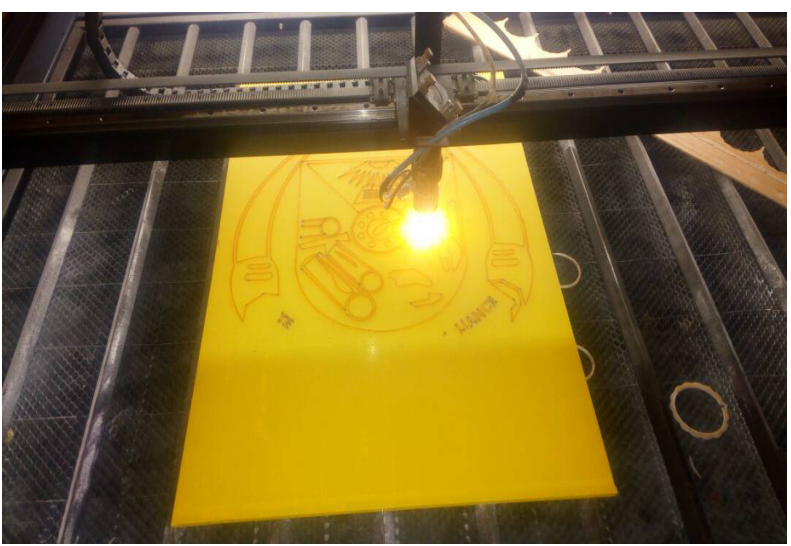

Tracing of logo design on resist sticker

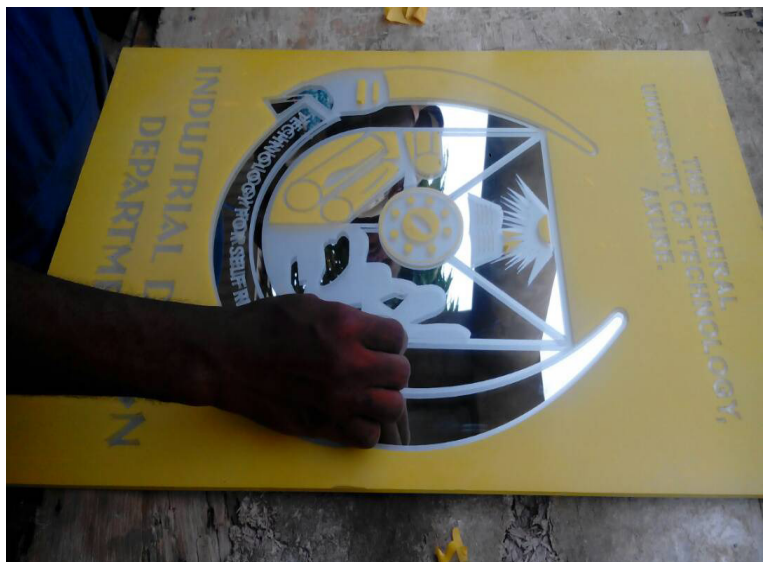

Removing the sticker

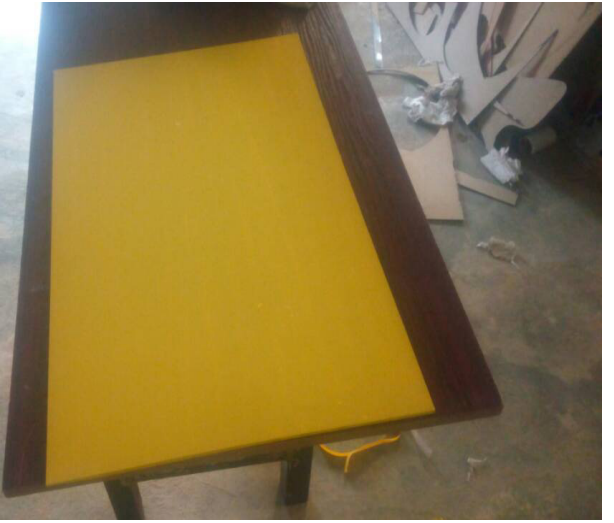

Covering glass surface with sticker

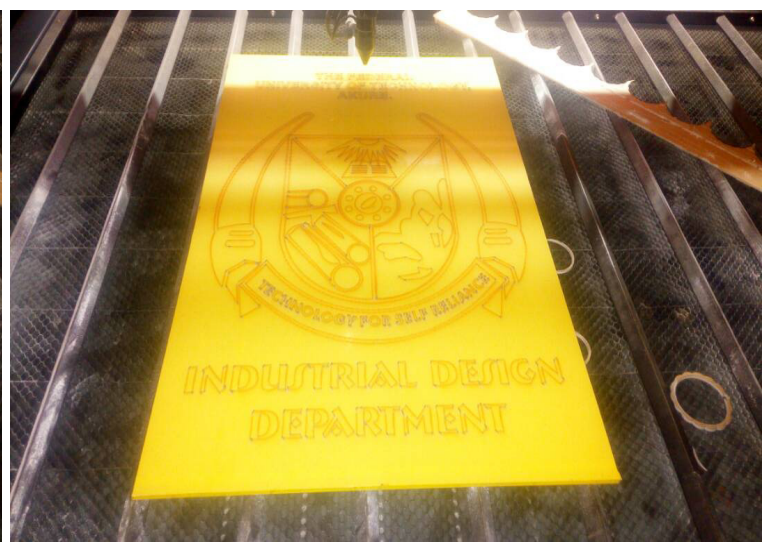

Blasting design on resist sticker
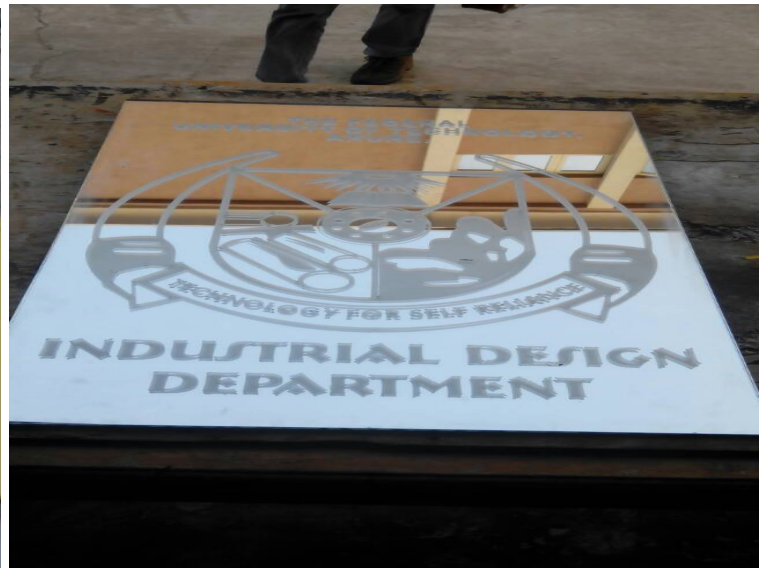

Completed logo design 


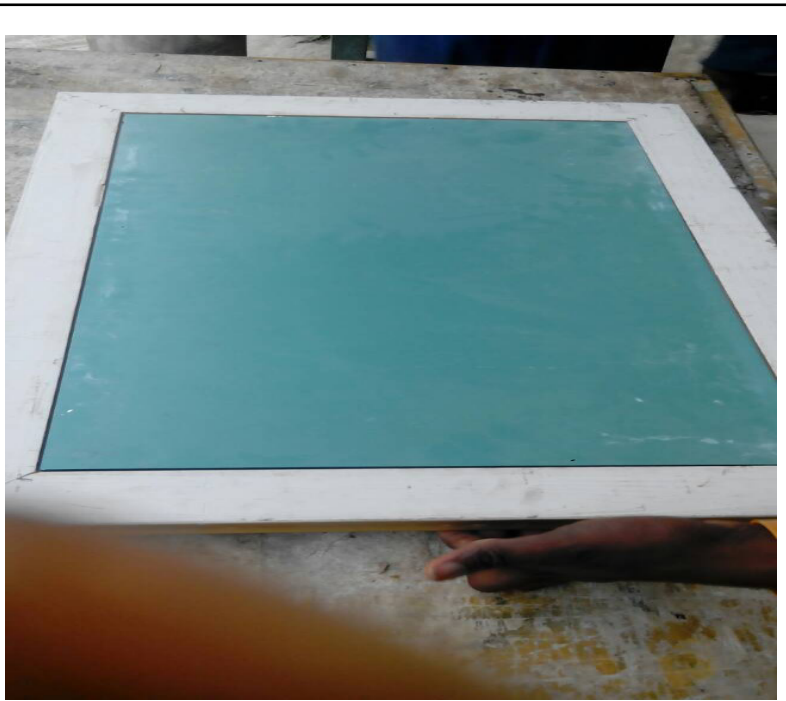

Framing of the design

\subsection{Discussion}

Glass mirrors used for this study were purchased from a local seller. The initial dimension of the glass mirror was $2000 \mathrm{~mm}$ by $1600 \mathrm{~mm}$ by $4 \mathrm{~mm}$. The researcher therefore took the first step of cutting the glass mirror to size. Three pieces of glass each of $600 \mathrm{~mm} \times 400 \mathrm{~mm} \times 4 \mathrm{~mm}$ was derived from the main piece. The researcher carried out unsuccessful blasting on the first two pieces in order to get used to the procedure and master the steps as well as how to use the sandblasting machine. The sandblasting machine used was rented from a glass fabricator at Arakale main market Akure, Ondo State, Nigeria. The fabricator insisted on carrying out the blasting in his presence for careful handling of the machine. Starting with the covering of the surface of the glass to the tracing of the resist (sticker), blasting and then the removal of the sticker, the process was rather time-consuming. Inspired by the vast literature of etched logo designs online, it was rather interesting to carry out the design of the logo and name of the university. Care of a fabricated glass surface is quite easy, only regular cleaning is required, so that the surface continues to glow.After achieving success with the design on the glass surface, it is very important to clean-up the workshop. The personal protective equipment at the fabrication workshop is quite poor. Equipment deficiencies and lack of proper maintenance are commonplace in such local workshops. Hence, workers are likely to receive above-TLV (Threshold Limit Value) quartz exposures and extreme noise exposures. Hazards related to electrical and mechanical equipment are most likely to occur if care is not taken. In such an open-air abrasive blasting like the one in this paper, anyone in close proximity may be exposed to safety and health hazards. It must be stated that the cleaning carried out within this study is way below the expected standard to clean-up abrasive materials. At the fabricating workshop, Cleaning was done by merely using a broom to wipe off blasting dust. In well-operated workshops with the modern machineries, A hand held cabinet type unit is generally are used for cleaning. Small parts that can be handheld or positioned on a rotatable mandrill is suitable. In such units the job and the abrasive are confined within a metal cabinet. Direction of the abrasive discharge is manually controlled. After the design was completed, it was framed in a wooden frame of similar dimension to the glass mirror. The completed glass mirror surface design bearing the name and logo of the FEDERAL UNIVERSITY OF TECHNOLOGY, AKURE was subsequently installed inside the industrial design studio within the depart of industrial design

\section{Conclusions}

The importance of glass as a tool for designs, decoration and beautification purposes in the twenty-first century cannot be over emphasized. As a result of the many experiences, the authors are of the opinion that more studies that pertain to fabrication with glass-based materials should be embarked upon within the industrial/manufacturing sector in Nigeria. This will further enhance the capacity of the fabricators in glass fabrication and design.

\section{References}

Asika, N. (2001). Research Methodologies in Behavioural Sciences. Lagos: Longman Nigeria PLC.

Black, K. (2010). Business Statistics: Contemporary Decision Makin (6th ed.). Oxford: John Wiley \& Sons. Dashiell, H. (1980). The Thin Man. New York: Avanel Books.

Encyclopædia Britannica. (2014, February 21). Etching. Retrieved February 14, 2018, from Encyclopædia Britannica: https://www.britannica.com/topic/etching-printing 
Enviro-Management \& Research, Inc. (2001). Abrasive blasting operations: Engineering Control and Work Practices Manual. Washington D.C.: National Institute for Occupational Safety and Health.

Farb, P. (1978). Man's Rise to Civilization. In E. W. Haury, The Hohokam: Deserts, Farmers and Craftsmen (p. 205). Rome: Walters.

Grosse, A., Grewe, M., \& Fouckhardt, H. (2001). Deep wet etching of fused silica glass for hollow capillary optical leaky waveguides in microfluidic devices. Journal of Micromechanis and Microengineering, 11, 257-262.

Kong, S., Minami, K., \& Esashi, M. (1997). Fabrication of reactive ion etching systems for deep silicon machining. IEEJ Transactions on Sensors and Micromachines, 117, 10-14.

Li, X., Abe, T., \& Esashi, M. (2000). Deep reactive ion etching of Pyrex glass. 13th Annual International Conference on Micro Electro Mechanical Systems (MEMS 2000), (pp. 271-276). Miyazaki, Japan.

Lin, C., Hsu, C., Yang, H., Wang, W., \& Fang, W. (2008). Implementation of silicon-on-glass MEMS devices with embedded through-wafer silicon vias using the glass reflow process for wafer-level packaging and 3D chip integration. Journal of Micromechanics and Microengineering, 18, 025018.

Marion, B., \& Omri, B. (1998). Setting the record straight. Printmaking Today, 7(4), 31-32.

Mbah, A. (2001). Research Methodology: A practical Guide to Research i n Fine, Applied and Performing Arts. Borno: Kamani Productions.

Omri, B. (1997). An improved method for steelfacing copper etching plates (Vol. 30). Leonardo: The MIT Press.

Saunders, M., Lewis, P., \& Thornhill, A. (2012). Research Methods for Business Students. Washington D.C.: Pearson Education Limited.

Toan, N. V., Miyashita, H., Toda, M., Kawai, Y., \& Ono, T. (2013). Fabrication of an hermetically packaged silicon resonator on LTCC substrate. Microsystems Technology, 19, 1165-1175.

Van Toan , N., Toda, M., \& On, T. (2016). An Investigation of Processes for Glass Micromachining. Micromachines, 51, 7. doi:10.3390/mi7030051

Wensink, H., Berenschot, J. W., Hanse, H. V., \& Elwenspoel, M. C. (2000). High resolution powder blast micromachining. 13th Annual International Conference on Micro Electro Mechanical Systems (MEMS 2000), (pp. 769-774). Miyazaki, Japan. 